\title{
Assessing Nonlinearity in Fish Habitat Preference of Japanese Medaka (Oryzias latipes) Using Genetic Algorithm-Optimized Habitat Prediction Models
}

\author{
Shinji FUKUDA ${ }^{1 *}$ and Shuji OKUSHIMA ${ }^{2}$ \\ ${ }^{1}$ Institute of Tropical Agriculture, Kyushu University (Fukuoka, Fukuoka 812-8581, Japan) \\ ${ }^{2}$ Department of Planning and General Administration, National Institute for Rural Engineering \\ (Tsukuba, Ibaraki 305-8609, Japan)
}

\begin{abstract}
The present study assessed nonlinearity in habitat preferences of Japanese medaka (Oryzias latipes) using genetic algorithm-optimized fuzzy habitat preference models incorporating the environmental factors of water depth (depth), current velocity (velocity), lateral cover ratio (cover), and percent vegetation coverage (vegetation). A linear relationship appeared between habitat preferences for cover and vegetation, which suggest the independent relationship between two factors. The habitat preference for velocity was found to have a nonlinear relationship with those for cover and vegetation, which appeared as different preference curves evaluated by the single-factor model. The habitat preference curves were affected by interactions between the environmental factors, especially those with nonlinear relationships, which resulted in different predictions of spatial distribution of the fish. Based on the present results, the use of a multiplex modeling approach, as applied in this study, would be appropriate to achieve better prediction accuracy, thus leading to more reliable habitat evaluation.
\end{abstract}

Discipline: Agricultural environment

Additional key words: freshwater fish, fuzzy reasoning, habitat evaluation, paddy environment, parameter optimization,

\section{Introduction}

Environmental degradation and the resulting decrease in habitats have become key issues of concern across the world. Several habitat-preference-based approaches have been proposed to assess the anthropogenic impacts on ecosystems, such as instream flow incremental methodology $\left(\mathrm{IFIM}^{3}\right)$ and habitat evaluation procedures $\left(\mathrm{HEP}^{19}\right)$, and these have been widely applied to assessments in both aquatic and terrestrial ecosystems. To evaluate habitat preferences of target species, researchers have proposed various types of the models, for instance, the habitat suitability index $\left(\mathrm{HSI}^{3,20}\right)$, patterns of preference level ${ }^{18}$, a fuzzy rule-based model ${ }^{13}$, and many others ${ }^{2,4-7,11,12}$. In nature, the habitat selections of target species are strongly affected by nonlinear and complex interactions between environmental factors, which is supported by previous researches using nonlinear equations in habitat prediction $^{9,10,21}$. From this perspective, the method used to evaluate the interactions is one of the most important aspects contributing to the reliability of habitat evaluation techniques. For instance, to test the reliability of regression equations, Vadas \& Orth $^{21}$ compared linear, polynomial, and product equations, and Guay et al. ${ }^{9,10}$ employed a logistic regression model to predict the spatial distribution of target fish. These studies employed a univariate approach, in which unit models that consider a single factor were developed and then these models were integrated to evaluate habitat preference based on several environmental factors. By contrast, a fuzzy rule-based model can express the interactions by using fuzzy sets, which reflect expert biological knowledge $e^{1,13,15,22}$. Despite these theoretical advances, no study has yet examined how habitat preferences would change under the effect of nonlinear interactions between environmental factors. Clarifying this issue would lead to a deeper understanding of habitat preferences, resulting in more reliable habitat assess-

*Corresponding author: e-mail shinji-fkd@agr.kyushu-u.ac.jp

Received 13 August 2007; accepted 8 November 2007. 
ments.

The present study aims to clarify the nonlinearity of habitat preferences for environmental factors and the effects of nonlinearity on the prediction of the spatial distribution of Japanese medaka (Oryzias latipes). This fish is a common species dwelling in paddy environments in Japan but now endangered, and thus becomes one of the symbols for rural environmental conservation in Japan. In the habitat evaluation, a fuzzy habitat preference model $\left(\right.$ FHPM $^{4,6,7}$ ) optimized by a genetic algorithm (GA) was employed. The interactions and the effects were then assessed using field data surveyed in an agricultural canal in Japan.

\section{Materials and methods}

\section{Study site}

The survey was carried out in an agricultural canal located in Kurume City, Fukuoka, Japan $\left(33^{\circ} 20^{\prime} \mathrm{N}\right.$, $\left.130^{\circ} 42^{\prime} \mathrm{E}\right)$. The spring-fed canal runs through paddy fields and is used for both irrigation and drainage purposes. It flows into the Kose River, which is a tributary of the Chikugo River. The fishes dwelling in this canal are cyprinids (Cyprinidae), loach (Cobitidae), catfish (Siluridae), snakehead (Channidae), goby (Gobiidae), and Japanese medaka ${ }^{16}$. Topminnow (Gambusia affinis), a species that competes with Japanese medaka, was not found in the canal.

\section{Field survey}

We established a 50-m-long study reach in the canal (1.6-2.0 $\mathrm{m}$ in width, $0.3 \%$ gradient; Fig. 1). A concrete agricultural facility is located approximately $31 \mathrm{~m}$ from the downstream end. The riparian zone of the reach was not covered with any trees or bushes.

The field surveys were conducted on 14 October and 5 November 2004 during a non-irrigation period so that the discharge in the reach remained stable. Therefore, the spatial distributions of Japanese medaka were not affected by any agricultural activities or agricultural chemicals. The water temperature remained relatively stable (16.1 - $18.6^{\circ} \mathrm{C}$ ) during the surveys. In addition, because the period of the survey is considered to be right after the end of the spawning season ${ }^{23}$, the number of the fish would also be stable.

The spatial distributions of Japanese medaka and the physical habitat characteristics of water depth (henceforth referred to as depth), current velocity (velocity), lateral cover ratio (cover), and percent vegetation coverage (vegetation) in the study reach were surveyed on sunny days. These four physical environmental factors previously were found to be the primary factors affecting the spatial distribution of the fish ${ }^{6}$. After mapping the reach, we observed the fish distribution (11:00-14:30) and then surveyed the physical habitat characteristics within the reach.

The spatial distribution of Japanese medaka was observed visually from the bank; the observer moved slowly and carefully to avoid disturbing the fish. The number of fish was counted in units of five to take into consideration the habit of school formation (i.e., fish in a small school of fewer than five individuals were not counted). Observations were repeated eight times and the results were averaged to reduce observational variance.

Immediately after completing the fish observations, the four physical habitat characteristics of depth, velocity, cover, and vegetation were surveyed to establish the relationships between the physical environment and habitat preferences of Japanese medaka. First, depth and velocity were measured and the study reach was divided into smaller water bodies having similar conditions with regard to these two physical parameters (Fig. 1). Depth was measured with a stainless steel rule and velocity with a portable propeller current meter (model V-303, Kenek, Tokyo, Japan) at three lateral points comprising a midpoint and two near-shore points at longitudinal intervals of $1 \mathrm{~m}$.

Next, the factors of cover and vegetation were calculated from the schematic diagrams of the water bodies (Fig. 1). The lateral cover ratio is defined as a function of the presence of lateral cover, which comprises the water's edge, a dike, or anything that emerges from the water surface and surrounds the water body. The cover thus con-

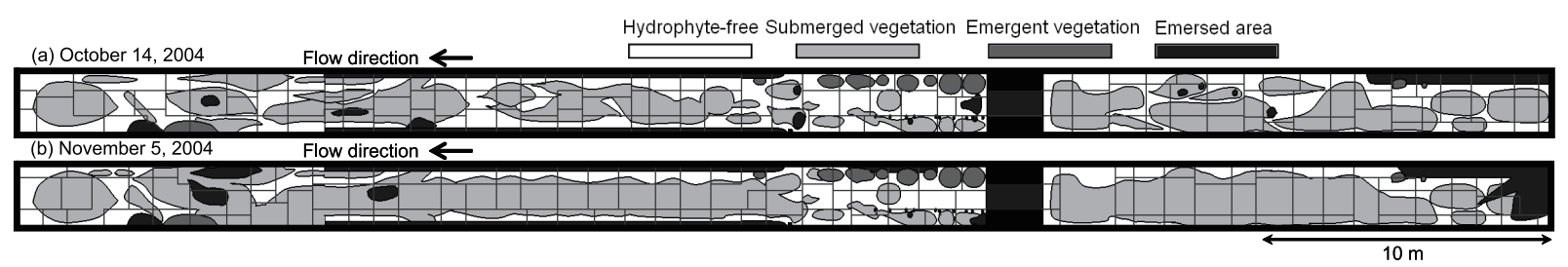

Fig. 1. Overview of study reach surveyed on (a) 14 October 2004 and (b) 5 November 2004

The solid lines depict the borders between water bodies. Each water body is assumed to have a uniform physical condition of water depth and current velocity. 
sists of four components (four lateral sides). The maximum cover ratio is $100 \%$, and each of the cover components is assigned a score of up to $25 \%$. In the definition of cover, objects attached to more than $90 \%$ of the boundary between water bodies (i.e., the solid lines in Fig. 1) were regarded as cover components. Thus, we considered only instream and undersurface cover structures that may have had the same effects as the margin of the stream. Percent vegetation coverage is defined as the percentage of the area covered with aquatic vegetation in each water body. Both submerged and emergent vegetation were pooled because of their similar roles in providing food and shelter from predators and fast-flowing currents.

The fish distribution data used in the following analyses were the observed fish population density obtained for the $i$ th water body, $\rho_{\mathrm{o}, i}$ (individuals $\left.\mathrm{m}^{-2}\right)$, where $i(i=$ $1,2, \ldots, n)$ denotes the index of the water body and $n$ the total number of water bodies.

\section{Habitat preference model}

In the present study, fish habitat preferences were evaluated using an FHPM to which fuzzy reasoning was introduced to relate physical habitat characteristics to habitat preference by considering uncertainties in fish behavior. In the FHPM, simplified fuzzy reasoning was used for its simplicity and a simple genetic algorithm (GA) was applied to optimize the model structure. The fuzzy membership functions shown in Fig. 2 reflect the ecology of Japanese medaka, and the general conditions are shown in Table 1. For instance, because the body length of an adult medaka is approximately $2 \mathrm{~cm}$, the critical requirements for Japanese medaka with regard to depth and velocity thus would be limited to relatively shallow and slowly flowing water. The singletons in the consequence part (a) Depth

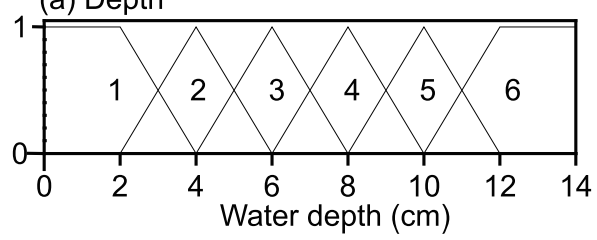

(b) Velocity

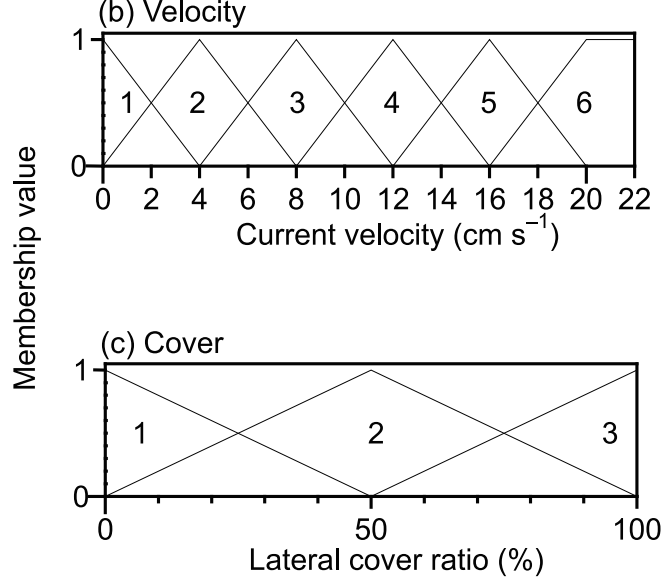

(d) Vegetation

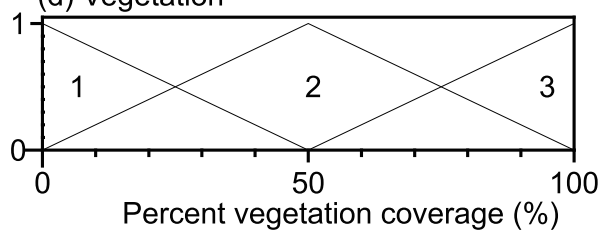

(i) Premise part (a) Depth

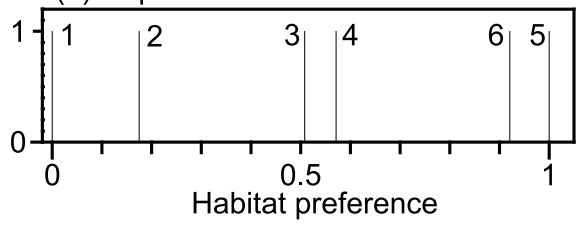

(b) Velocity

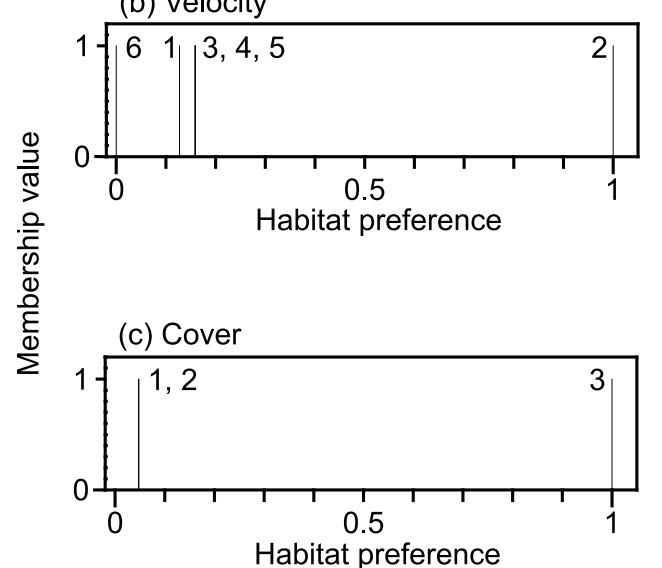

(d) Vegetation

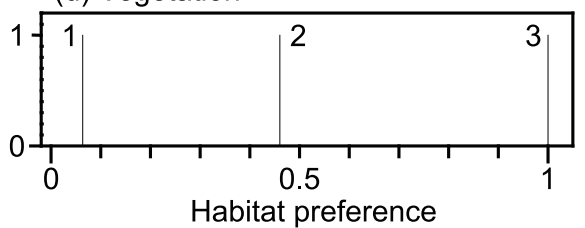

(ii) Consequence part

Fig. 2. An example of premise and consequence parts of a fuzzy habitat preference model

The numbers in the premise part correspond to those in the consequence part. The premise parts are predefined and the consequence parts are determined by using a genetic algorithm. See text for more details. 
Table 1. Conditions for fuzzy habitat preference model

\begin{tabular}{|c|c|}
\hline General & $\begin{array}{l}\text { Preference curves are defined to be in the range from zero to unity. } \\
\text { Preference curves should be monotonic increase, unimodal, or monotonic decrease. } \\
\text { At least one of the singletons in consequence part of each factor should have a value of unity. } \\
\text { Ten different intial conditions are given in parameter optimization using a GA. }\end{array}$ \\
\hline Depth & $\begin{array}{l}\text { Fuzzy set for depth consists of six membership functions (Fig. 2a). } \\
\text { Preference at the area less than } 2 \mathrm{~cm} \text { depth is fixed to be zero (membership function 1) } \\
\text { - fish require a depth of at least three times their body length to inhabit a stream }{ }^{14}-\end{array}$ \\
\hline Velocity & $\begin{array}{l}\text { Fuzzy set for velocity consists of six membership functions (Fig. 2b) } \\
\text { — swimming ability must be limitation in habitat selection of Japanese medaka - }\end{array}$ \\
\hline $\begin{array}{l}\text { Cover \& } \\
\text { Vegetation }\end{array}$ & $\begin{array}{l}\text { Fuzzy sets for cover and vegetation consist of three membership functions to cover all the range } \\
\text { of the factors (Figs. } 2 \text { c-d). }\end{array}$ \\
\hline
\end{tabular}

were optimized using a GA to minimize the mean square error (MSE) between predicted and observed fish population density. The optimization procedure was as follows.

First, a GA gave the initial model structure of the FHPM. Second, the input values were represented by symmetric triangular fuzzy numbers to take into account the uncertainties caused by measurement errors and spatial dispersions. Each fuzzy input is expressed by its center and spread, of which the center is the environmental measurement and the spread is determined from the allowable variance when dividing the reach into water bodies: $1 \mathrm{~cm}$ for the spread of depth, $2 \mathrm{~cm} \mathrm{~s}^{-1}$ for velocity, and $10 \%$ each for cover and vegetation. Together with the initial FHPM and fuzzy input values, habitat preferences for each environmental factor were then calculated. Next, the habitat preferences for the four environmental factors were integrated using the following equation:

$$
P_{i}=P_{\mathrm{d}, i} \times P_{\mathrm{v}, i} \times P_{\mathrm{c}, i} \times P_{\mathrm{veg}, i},
$$

where $P_{i}$ denotes the habitat preference in the ith water body and the subscripts $\mathrm{d}, \mathrm{v}, \mathrm{c}$, and veg represent the factors depth, velocity, cover, and vegetation, respectively. Although there would be some discussions regarding which method should be used with composite preferences, we used Eq. (1) based on the study by Vadas and Orth ${ }^{21}$, which reported that this product equation would be superior to other methods such as linear regression. Next, the spatial distribution of Japanese medaka was predicted by using the following equation:

$$
\rho_{\mathrm{c}, i}=\left(P_{i} / \sum_{i=1}^{n} P_{i}\right) \cdot \sum_{i=1}^{n} \rho_{\mathrm{o}, i},
$$

where $\rho_{\mathrm{c}, i}$ is the calculated fish population density in the ith water body and $\rho_{\mathrm{c}, i}$ is the observed density. The MSE between the predicted and observed fish population density was then calculated, and the GA repeatedly modified the singletons to minimize the MSE. Finally, the opti- mized FHPM was obtained.

Accordingly, the reliability of FHPM is evaluated by the accuracy of how this model can predict fish population density of Japanese medaka.

\section{Analysis}

To assess nonlinearity between fish habitat preferences for environmental factors, 15 combinations of FHPM (four single-factor FHPMs, six two-factor FHPMs, four three-factor FHPMs, and a four-factor FHPM) were developed using the normalized fish population density for considering the generality and independence of the two surveys in this study. In each combination, model parameters were optimized simultaneously by the GA, in which 10 different initial conditions were given. After the optimization, habitat preference curves were plotted for each combination of factors. The spatial distribution of Japanese medaka was predicted by the 15 FHPMs using the actual fish population density. In addition to the above models, one model comprised of the four single-factor FHPMs of depth, velocity, cover, and vegetation was applied to the above prediction, in which the four singlefactor models were integrated using Eq. (1). The effects of nonlinearity on habitat preference were then assessed based on the preference curves and prediction errors. In the present analysis, the nonlinear effects would appear as different preference curves between single-factor and multiple-factor FHPMs.

\section{Results}

Based on the two surveys on 14 October and 5 November 2004, the fish population density observed in the entire reach totaled 404 individuals $\mathrm{m}^{-2}$ in the former and 356 individuals $\mathrm{m}^{-2}$ in the latter. The maximum population density in a water body was 42.9 individuals $\mathrm{m}^{-2}$ in the former and 35.4 individuals $\mathrm{m}^{-2}$ in the latter. These data may suggest the congregation of the fish in some part 


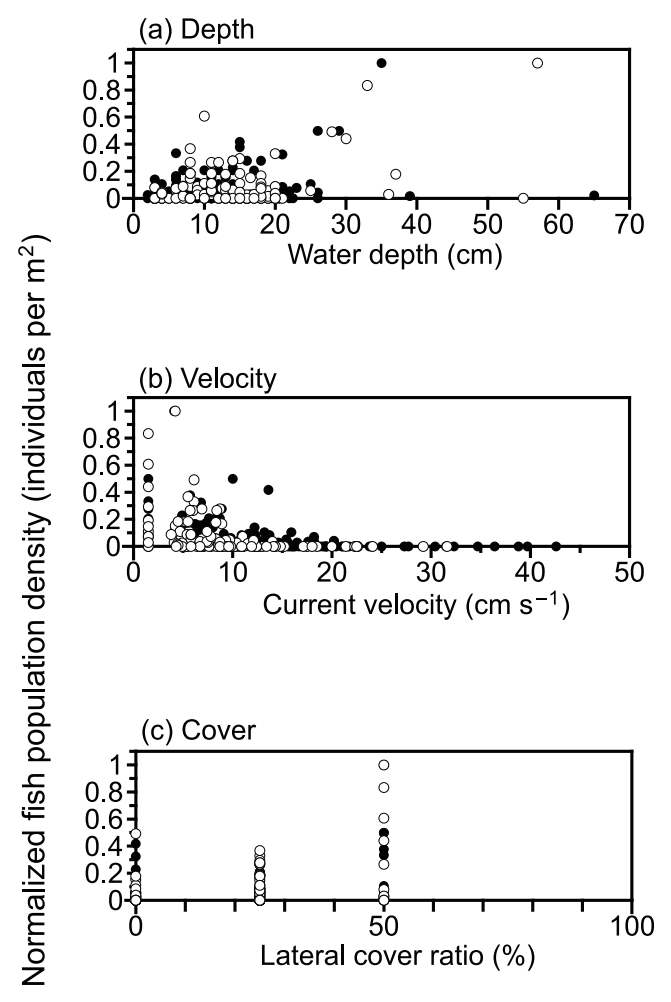

(d) Vegetation

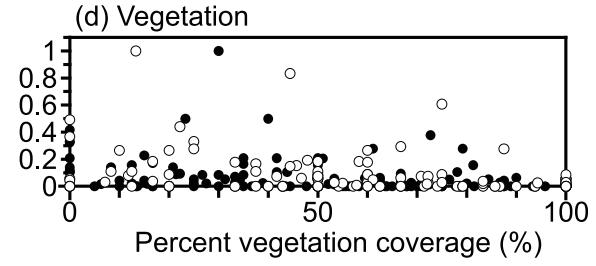

Fig. 3. Results of the field surveys on 14 October (filled circle) and 5 November (open circle) 2004 in which fish population density was normalized to the maximum value in each survey

of the canal. Because each survey was conducted independently, the results were pooled for the following analyses. To evaluate the habitat preferences, the fish population density was normalized to each maximum density (Fig. 3). By contrast, the actual fish population density was used when predicting the spatial distribution of Japanese medaka. There were no significant correlations between the four physical conditions observed in the surveys.

Habitat preference curves evaluated by FHPM under 10 different initial conditions are shown in Fig. 4 for single-factor FHPMs, Fig. 5 for two-factor FHPMs, Fig. 6 for three-factor FHPMs, and Fig. 7 for the four-factor FHPM. The curves resulted in good convergence in all the cases and were found to be slightly different between models. In Fig. 4, every habitat preference curve presents a mono- (a) Depth

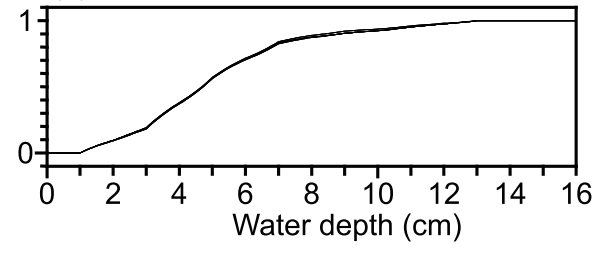

(b) Velocity

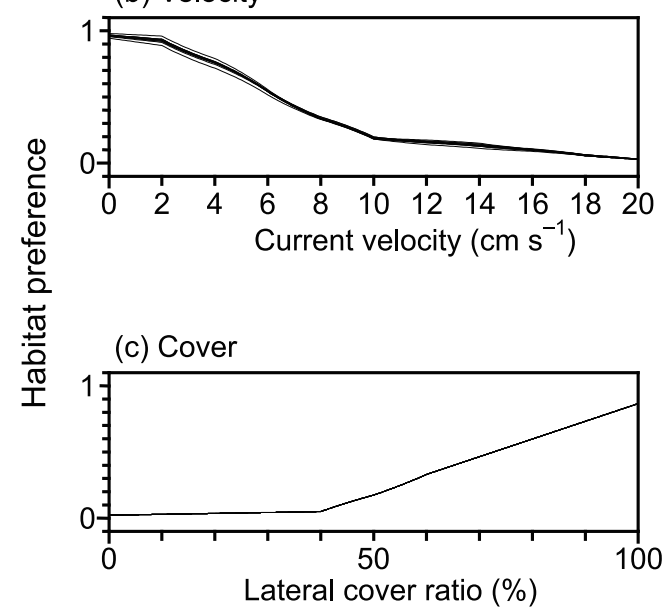

(d) Vegetation

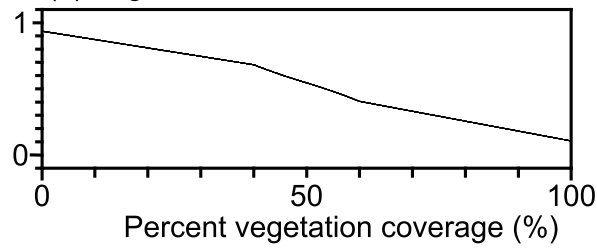

Fig. 4. Habitat preference curves evaluated by four single-factor FHPMs under 10 different initial conditions

tonic increase or decrease with the physical condition. The cases of cover and vegetation appear to indicate a linear relationship between habitat preferences because the preference curves maintained the same trend with no fluctuation (Figs. 4, 5). However, some preference curves for velocity were unimodal (Figs. 5d, 5e, 6a, 6d, 7), which may be attributed to nonlinear relationships between the habitat preference for velocity and those for cover and vegetation.

Figure 8 depicts the spatial distribution of Japanese medaka predicted using the FHPMs, in which the best prediction among 10 trials is shown; the prediction results are summarized in Table 2. Despite the slight differences in habitat preference curves (Figs. 4-7), the prediction errors differed considerably. The single-factor FHPMs could not describe the spatial distribution (mostly underestimated, 
(a) Depth and Velocity

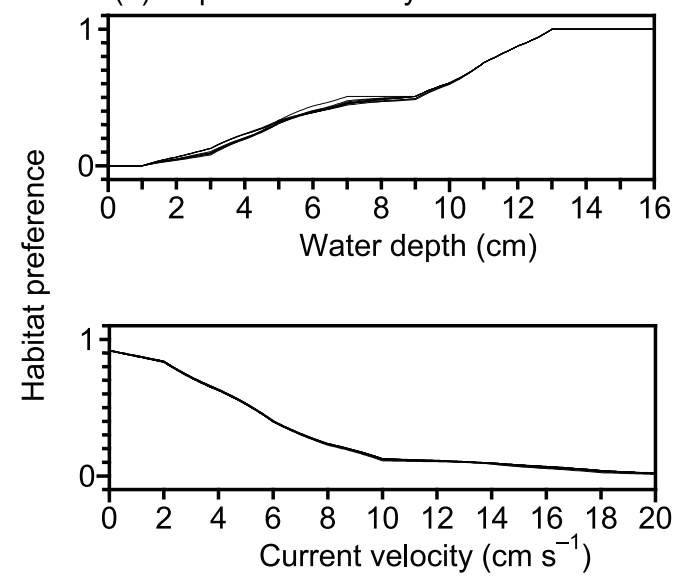

(c) Depth and Vegetation

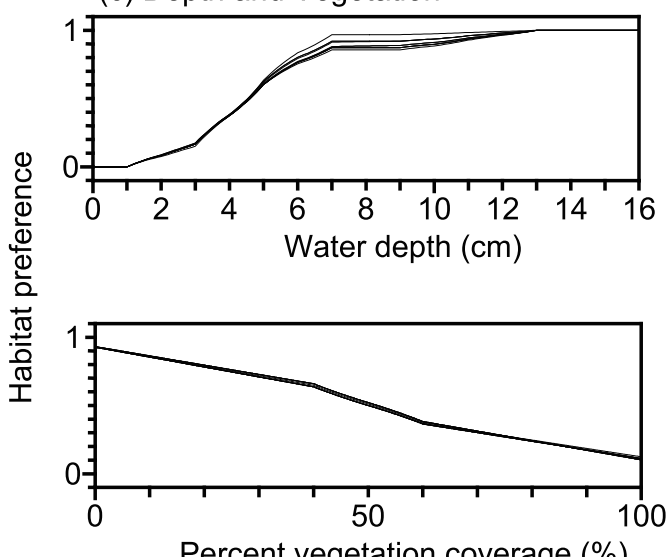

(e) Velocity and Vegetation

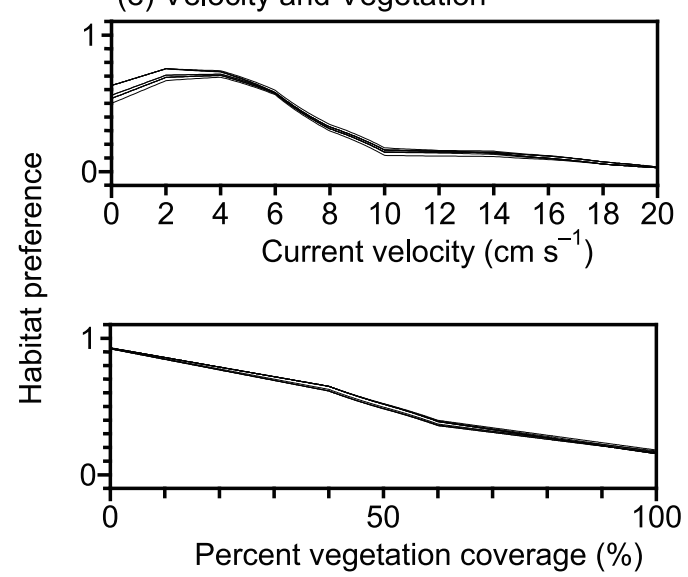

(b) Depth and Cover

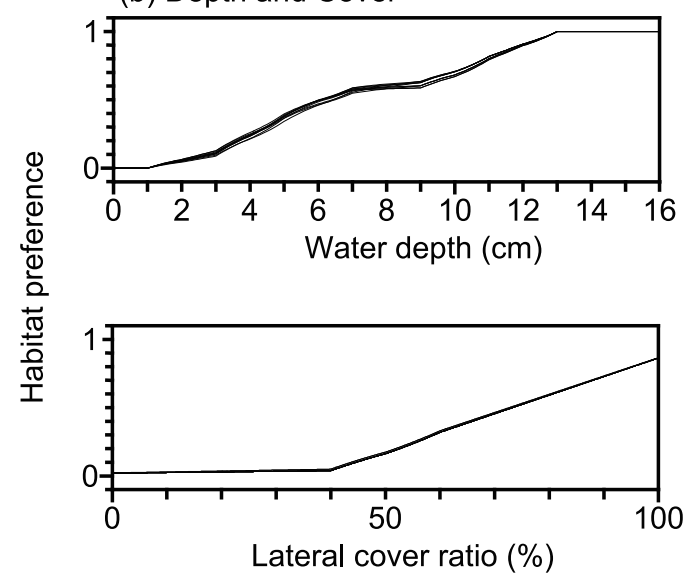

(d) Velocity and Cover
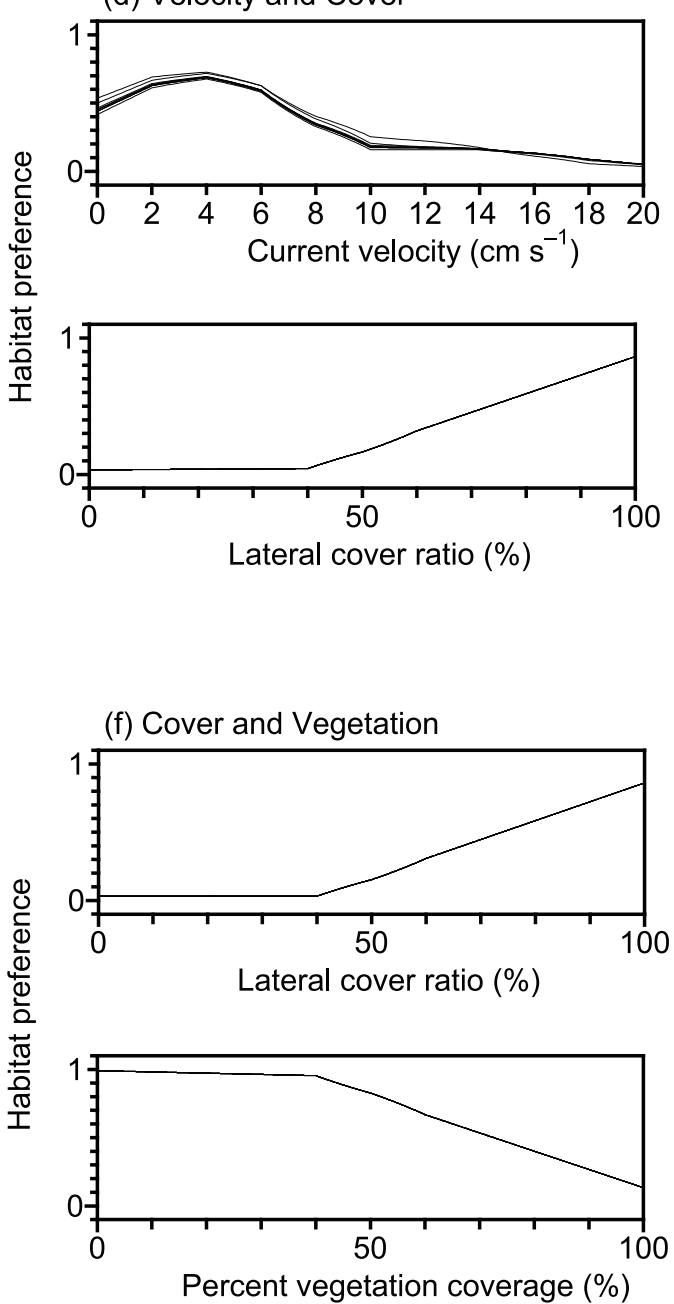

Fig. 5. Habitat preference curves evaluated by six two-factor FHPMs under 10 different initial conditions 
(a) Depth, Velocity and Cover
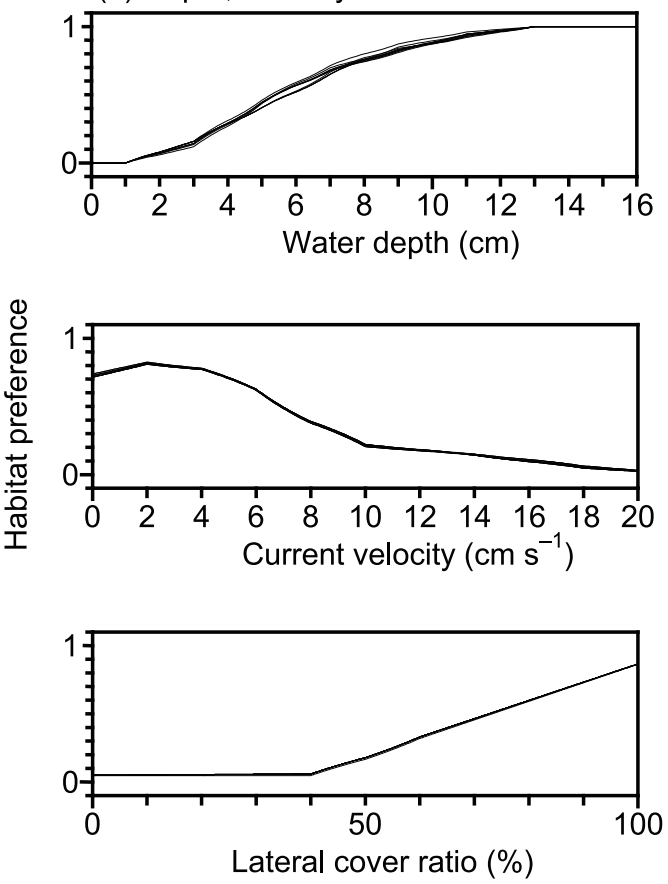

(c) Depth, Cover and Vegetation
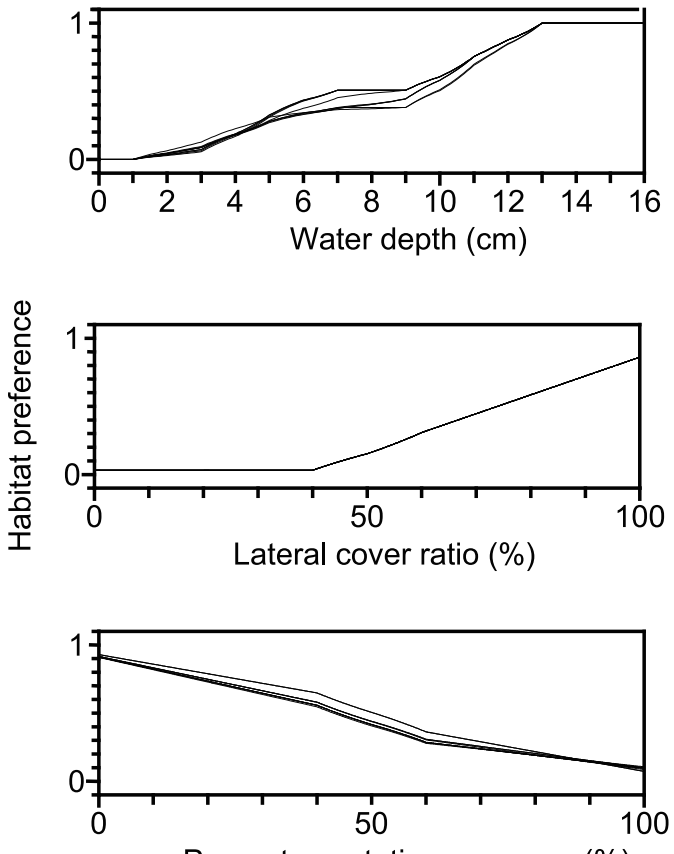

Percent vegetation coverage (\%) (b) Depth, Velocity and Vegetation
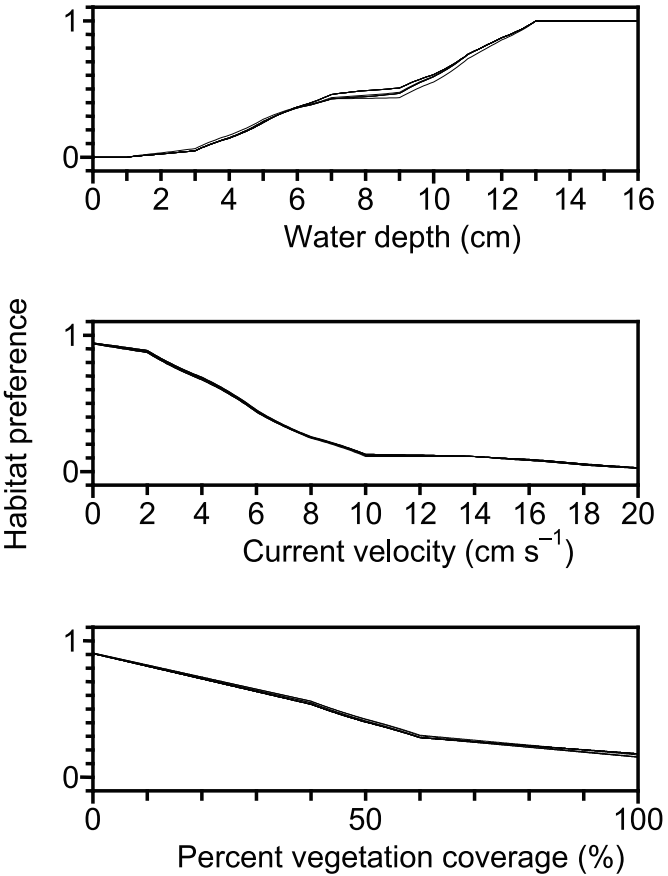

(d) Velocity, Cover and Vegetation
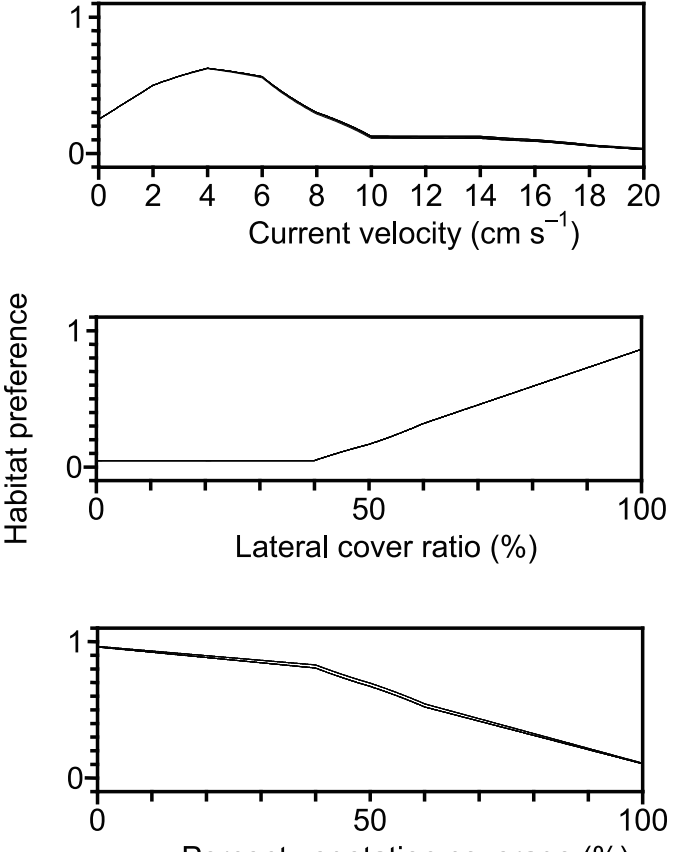

Percent vegetation coverage (\%)

Fig. 6. Habitat preference curves evaluated by four three-factor FHPMs under 10 different initial conditions 
(a) Depth

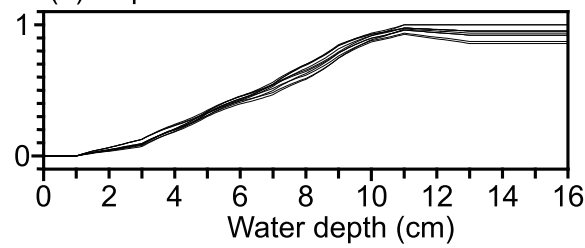

(b) Velocity

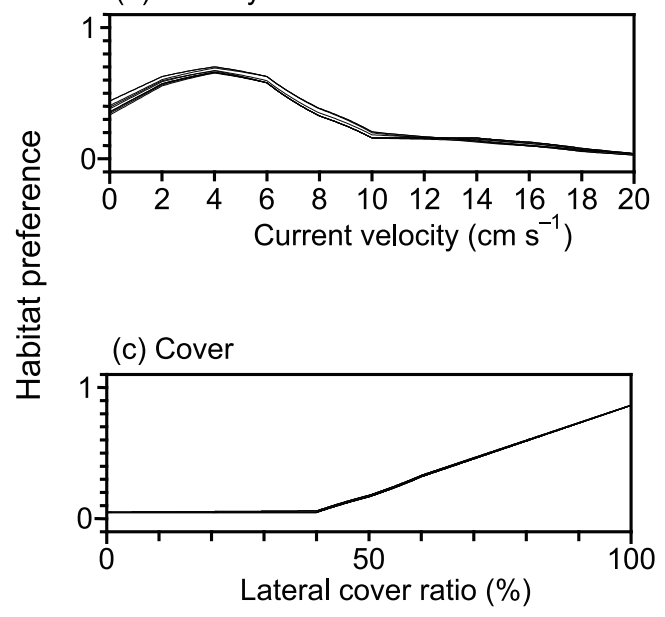

(d) Vegetation

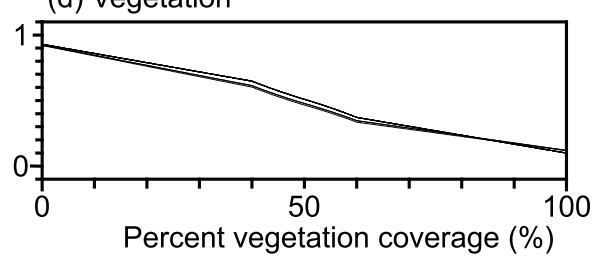

Fig. 7. Habitat preference curves evaluated by a four-factor FHPM under 10 different initial conditions

Figs. 8a-d). In the two-factor models, some combinations were unable to improve the prediction of the single-factor models (Figs. 8e-j). By contrast, the three-factor FHPMs resulted in better accuracy than single- and two-factor models (Figs. 8k-n), as did the four single-factor integrated model (Fig. 8p). Among all the models, the fourfactor multiplex model (Fig. 80) provided the best prediction. As shown in Table 2, the standard deviation of prediction errors increased as more factors were considered. This corresponds to the fluctuations in habitat preference curves, which might reflect nonlinear, uncertain interactions in habitat preference.

\section{Discussion}

The preference curves derived from the 15 FHPMs enabled us to investigate the interactions between habitat preferences for the four environmental factors (Figs. 4-7). A linear relationship between habitat preferences for cover and vegetation is evident because there was no correlation between these two physical conditions and the preference curves converged quite well under the condition of two-factor integration (Figs. 4c, 4d, 5f). Under such linear relationships, a univariate approach based on a single-factor model can be used, as is widely applied in general habitat modeling $3,8,19,20$. In contrast, the present analyses revealed a nonlinear relationship between habitat preference for velocity and those for cover and vegetation, which resulted in unimodal curves for velocity when combined with the factors of cover and vegetation (Figs. 4, 5d, 5e, 6a, 6d, 7). These unimodal curves for velocity imply that Japanese medaka prefer slowly flowing water rather than stagnant water, which may result from a bioenergetic consequence between energy intake (food) and swimming $\operatorname{cost}^{17}$. Avoidance of larger vegetation coverage would be for the same reason. In any case, it is quite difficult to clarify the causes of nonlinearity in habitat preference because it can be affected by physical environments as well as the internal condition of Japanese medaka. The nonlinear relationship suggests the use of the multiplex approach as employed in this study. These linear and nonlinear relationships would be due to the complexity of habitat preferences and the actual physical conditions in a given environment. In other words, these relationships may reflect a balance between habitat preferences and habitat availability. To clarify these potentially divergent factors, a previous study ${ }^{6}$ mathematically evaluated relative importance of these environmental factors and cover was found to have the highest significance in predicting fish distribution of Japanese medaka. Such an information-theoretic approach would enable us to assess the significance of the factors under consideration.

Based on our findings, the consideration of nonlinearity in habitat preference is important for achieving a reliable habitat assessment. That is, users should be careful when selecting a modeling approach because a nonlinear relationship affects habitat preference curves, which leads to different prediction results (Fig. 8, Table 2). The differences in habitat preference curves would affect the assessment results of a preference-based approach, such as IFIM $^{3}$ or $\mathrm{HEP}^{19}$, in which the habitat quality of the site is evaluated by summing the products of habitat preference times the surface area of each water body (known as weighted usable area). Application of the multiplex modeling approach may cover the complexity and uncertainty inherent in habitat preference and selection under natural conditions. However, further studies on these issues are necessary for the reliable habitat assessment because the habitat preference curves for Japanese medaka were eval- 

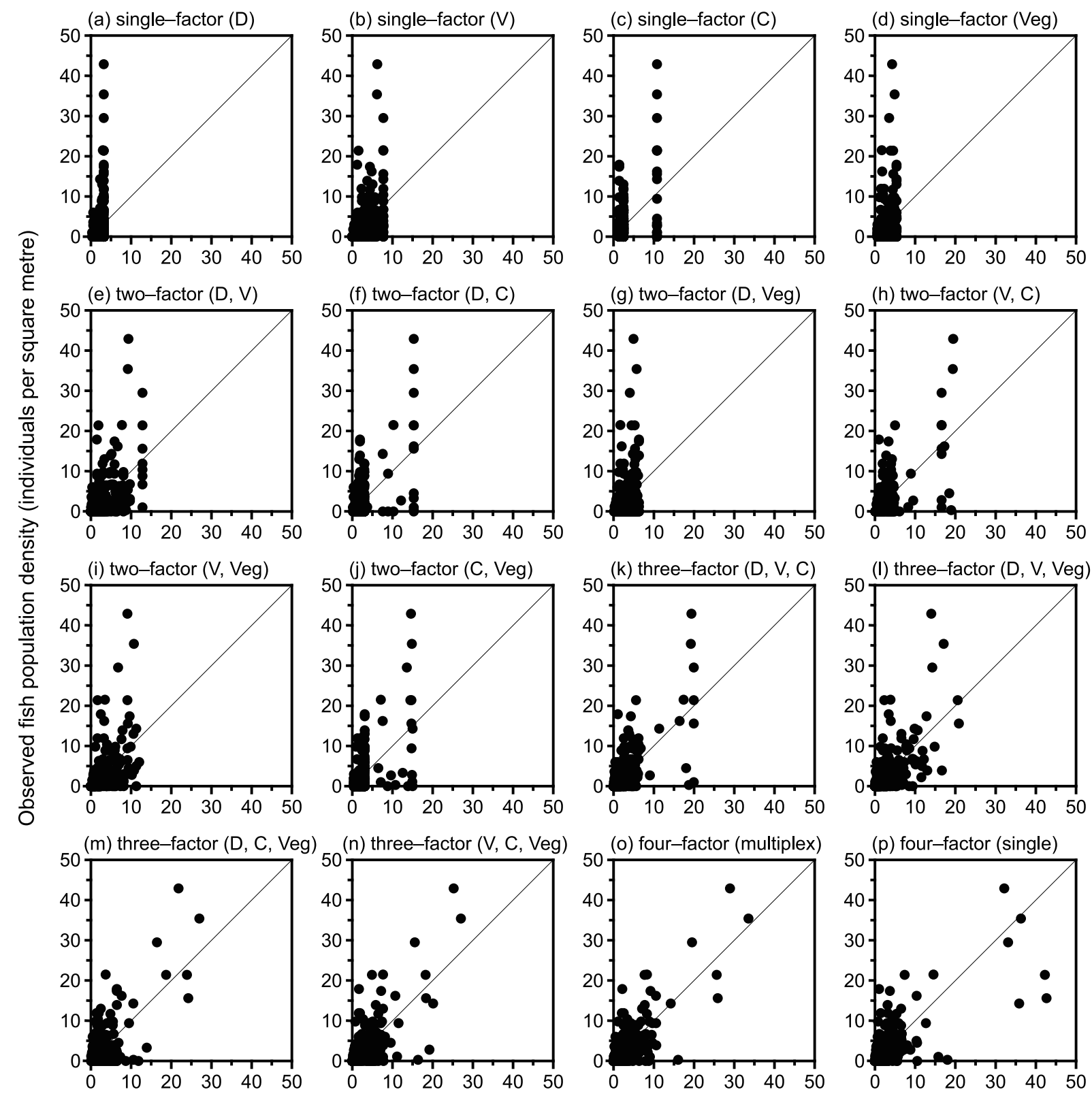

Predicted fish population density (individuals per square metre)

Fig. 8. Scatter diagrams of predicted and observed fish population density using 16 different FHPMs; the best prediction is shown, except for part (p)

uated based on the relationship between fish population density and physical conditions observed in the canal. The generality of the model, often characterized as transferability, is another problem to be considered in habitat modeling, which might be ascribed to factors such as seasonal changes and inter- and intraspecific competition.

In conclusion, the present study assessed nonlinear relationships in habitat preferences between the four environmental factors of depth, velocity, cover, and vegetation in Japanese medaka. Habitat preferences for cover and vegetation were found to have a linear relationship, whereas habitat preference for velocity had a nonlinear relationship with those for cover and vegetation. Because habitat preference curves are affected by the interactions between environmental factors, it is suggested that the multiplex modeling approach should be employed to achieve more accurate predictions. Further studies focusing on complex interactions of other factors, such as seasonal changes and competition among species, are required for a deeper understanding and quantification of habitat preferences of target species. To achieve this, an approach based on laboratory experiments ${ }^{12,18}$ would be 
Table 2. Mean squared errors between predicted and observed fish population density calculated by 16 FHPMs under 10 different initial conditions, except for the four single-factor integrated model (last row)

\begin{tabular}{|c|c|c|c|c|c|}
\hline Type & & Minimum & Mean & Maximum & SD \\
\hline \multirow[t]{4}{*}{ Single-factor } & $\mathrm{D}$ & 28.20 & 28.20 & 28.20 & 0.001 \\
\hline & $\mathrm{V}$ & 23.23 & 23.23 & 23.25 & 0.005 \\
\hline & $\mathrm{C}$ & 22.42 & 22.42 & 22.42 & 0.000 \\
\hline & Veg & 26.14 & 26.14 & 26.14 & 0.000 \\
\hline \multirow[t]{6}{*}{ Two-factor } & $\mathrm{D}, \mathrm{V}$ & 20.49 & 20.50 & 20.51 & 0.004 \\
\hline & $\mathrm{D}, \mathrm{C}$ & 20.21 & 20.23 & 20.28 & 0.020 \\
\hline & $\mathrm{D}, \mathrm{Veg}$ & 25.51 & 25.52 & 25.53 & 0.005 \\
\hline & $\mathrm{V}, \mathrm{C}$ & 16.82 & 16.84 & 16.90 & 0.025 \\
\hline & V, Veg & 20.62 & 20.65 & 20.70 & 0.023 \\
\hline & C, Veg & 19.78 & 19.78 & 19.78 & 0.000 \\
\hline \multirow[t]{4}{*}{ Three-factor } & $\mathrm{D}, \mathrm{V}, \mathrm{C}$ & 15.32 & 15.33 & 15.35 & 0.012 \\
\hline & $\mathrm{D}, \mathrm{V}, \mathrm{Veg}$ & 16.44 & 16.48 & 16.51 & 0.022 \\
\hline & $\mathrm{D}, \mathrm{C}, \mathrm{Veg}$ & 15.78 & 15.87 & 15.95 & 0.065 \\
\hline & V, C, Veg & 13.70 & 13.72 & 13.73 & 0.015 \\
\hline Four-factor (multiplex) & $\mathrm{D}, \mathrm{V}, \mathrm{C}, \mathrm{Veg}$ & 10.68 & 10.74 & 10.82 & 0.052 \\
\hline Four-factor (integrated) & D, V, C, Veg & - & 17.33 & - & - \\
\hline
\end{tabular}

D: depth, V: velocity, C: cover, Veg: vegetation.

SD: standard deviation.

appropriate for controlling the physical and ecological conditions to be considered.

\section{Acknowledgments}

The authors thank Prof. Dr. K. Hiramatsu (Faculty of Agriculture, Kyushu University, Japan) for his generous and capable assistance in all phases of this study. We also appreciate the assistance of Dr. M. Mori (Faculty of Agriculture, Kochi University, Japan) and Mr. K. Abe (Taiyo Consultants, Japan) in the field surveys. This study was partly supported by Grant-in-Aid for Young Scientists (Start-up), JSPS, Japan.

\section{References}

1. Adriaenssens, V., Goethals, P. L. M. \& De Pauw, N. (2006) Fuzzy knowledge-based models for prediction of Asellus and Gammarus in watercourses in Flanders (Belgium). Ecol. Model., 195, 3-10. DOI: 10.1016/j.ecolmodel. 2005.11.043.

2. Ahmadi-Nedushan, B. et al. (2006) A review of statistical methods for the evaluation of aquatic habitat suitability for instream flow assessment. River Res. Appl., 22, 503-523. DOI: $10.1002 /$ rra.918.

3. Bovee, K. D. et al. (1998) Stream habitat analysis using the instream flow incremental methodology. U.S. Geological Survey, Biological Resources Division Information and
Technology Report, USGS/BRD-1998-0004.

4. Fukuda, S. et al. (2005) Mathematical characterization of fuzziness in fish habitat preference of Japanese medaka (Oryzias latipes) in agricultural canal. Trans. JSIDRE, 239, 43-49 [In Japanese with English summary].

5. Fukuda, S., Hiramatsu, K. \& Mori, M. (2006) Fuzzy neural network model for habitat prediction and HEP for habitat quality estimation focusing on Japanese medaka (Oryzias latipes) in agricultural canals. Paddy Water Environ., 4(3), 119-124. DOI: 10.1007/s10333-006-0039-5.

6. Fukuda, S., Hiramatsu, K. \& Okushima, S. (2006) An information-theoretic approach for the model selection in habitat preference evaluation of Japanese medaka (Oryzias latipes). Bull. Inst. Trop. Agric. Kyushu Univ., 29, 105-118.

7. Fukuda, S. et al. (2006) Numerical quantification of the significance of aquatic vegetation affecting spatial distribution of Japanese medaka (Oryzias latipes) in an agricultural canal. Landscape Ecol. Eng., 2, 65-80. DOI: 10.1007/ s11355-006-0030-8.

8. Fukuda, S. \& Hiramatsu, K. (2007) Prediction ability of resource selection functions for the estimation of fish habitat preference. Trans. JSIDRE, 247, 113-118.

9. Guay, J. C. et al. (2000) Development and validation of numerical habitat models for juveniles of Atlantic salmon (Salmo salar). Can. J. Fish. Aquat. Sci., 57, 2065-2075.

10. Guay, J. C. et al. (2003) Assessment of the transferability of biological habitat models for Atlantic salmon parr (Salmo salar). Can. J. Fish. Aquat. Sci., 60, 1398-1408.

11. Harby, A. et al., eds. (2004) COST Action 626 report: Stateof-the-art in data sampling, modelling analysis and applications of river habitat modelling. COST Action 626 Euro- 
pean Aquatic Modelling Network.

12. Hiramatsu, K., Fukuda, S. \& Shikasho, S. (2003) Mathematical modeling of habitat preference of Japanese medaka for instream water environment using fuzzy inference. Trans. JSIDRE, 228, 65-72 [In Japanese with English summary].

13. Jorde, K. et al. (2001) Fuzzy-based models for the evaluation of fish habitat quality and instream flow assessment. In Proceedings of the 2001 international symposium on environmental hydraulics, Tempe, AZ, CD-ROM.

14. Morishita, I. \& Morishita, Y. (1997) Kyosei no shizengaku, stream organisms in Japan: how they are affected by Japanese culture and how they express ecological health. Sankaido, Tokyo [In Japanese with English description].

15. Mouton, A. S. et al. (2007) Fish habitat modelling as a tool for river management. Ecol. Eng., 29, 305-315. DOI: 10.1016/j.ecoleng.2006.11.002.

16. Oohira, Y., Nakano, Y. \& Yuge, K. (2005) Environmental restoration target of irrigation and drainage channels based on the observation of aquatic animals. Sci. Bull. Fac. Agric. Kyushu, 60(2), 233-251 [In Japanese with English summary].

17. Rosenfeld, J. S. \& Boss, S. (2001) Fitness consequences of habitat use for juvenile cutthroat trout: energetic costs and benefits in pools and riffles. Can. J. Fish. Aquat. Sci., 58, 585-593.

18. Sekine, M., Imai, T. \& Ukita, M. (1997) A model of fish distribution in rivers according to their preference for environmental factors. Ecol. Model., 104, 215-230.

19. U.S. Fish and Wildlife Service (1980) Habitat evaluation procedures (HEP). Ecological service manual 102. U.S. Fish and Wildlife Service, Washington, D.C.

20. U.S. Fish and Wildlife Service (1980) Standards for the development of habitat suitability index models. Ecological service manual 103. U.S. Fish and Wildlife Service, Washington, D.C.

21. Vadas, R. L. \& Orth, D. J. (2001) Formulation of habitat suitability models for stream fish guilds: Do the standard methods work? Trans. Am. Fish. Soc., 130, 217-235.

22. Van Broekhoven, E. et al. (2006) Fuzzy rule-based macroinvertebrate habitat suitability models for running waters. Ecol. Model., 198, 71-84.

23. Yoshioka, H. (1963) On the effects of environmental factors upon the reproduction of fishes: 2 . Effects of short and long day-lengths on Oryzias latipes during spawning season. Bull. Fac. Fish. Sci. Hokkaido Univ., 14(3), 137-151. 